\title{
Mitochondrial RNase P RNAs in ascomycete fungi: Lineage-specific variations in RNA secondary structure
}

\author{
ELIAS R. SEIF, ${ }^{1}$ LISE FORGET, ${ }^{1}$ NANCY C. MARTIN, ${ }^{2}$ and B. FRANZ LANG ${ }^{\mathbf{1}}$ \\ ${ }^{1}$ Program in Evolutionary Biology, Canadian Institute for Advanced Research, Département de Biochimie, Université de Montréal, \\ Montréal, Québec H3T 1J4, Canada \\ ${ }^{2}$ University of Louisville, Department of Biochemistry and Molecular Biology, School of Medicine, University of Louisville, \\ Louisville, Kentucky 40292-0001, USA
}

\begin{abstract}
The RNA subunit of mitochondrial RNase $\mathbf{P}(\mathrm{mtP}-\mathrm{RNA})$ is encoded by a mitochondrial gene ( $r n p B)$ in several ascomycete fungi and in the protists Reclinomonas americana and Nephroselmis olivacea. By searching for universally conserved structural elements, we have identified previously unknown rnpB genes in the mitochondrial DNAs (mtDNAs) of two fission yeasts, Schizosaccharomyces pombe and Schizosaccharomyces octosporus; in the budding yeast Pichia canadensis; and in the archiascomycete Taphrina deformans. The expression of mtP-RNAs of the predicted size was experimentally confirmed in the two fission yeasts, and their precise 5' and 3' ends were determined by sequencing of cDNAs generated from circularized mtP-RNAs. Comparative RNA secondary structure modeling shows that in contrast to mtP-RNAs of the two protists $R$. americana and $N$. olivacea, those of ascomycete fungi all have highly reduced secondary structures. In certain budding yeasts, such as Saccharomycopsis fibuligera, we find only the two most conserved pairings, P1 and P4. A P18 pairing is conserved in Saccharomyces cerevisiae and its close relatives, whereas nearly half of the minimum bacterial consensus structure is retained in the RNAs of fission yeasts, Aspergillus nidulans and Taphrina deformans. The evolutionary implications of the reduction of mtP-RNA structures in ascomycetes will be discussed.
\end{abstract}

Keywords: Evolution; phylogenetic modeling; RNA processing; organelle; rnpB; yeasts

\section{INTRODUCTION}

RNase $\mathrm{P}$ is a ribonucleoprotein (for exceptions, see below) that is universally present in eubacteria, archaebacteria, and eukaryotes, as well as in mitochondria and chloroplasts. It participates in the processing of tRNAs, $4.5 \mathrm{~S}$ RNAs, and other small RNAs, by endonucleolytic removal of $5^{\prime}$ leader sequences from RNA precursors (Peck-Miller and Altman 1991).

The RNA subunits of eubacterial RNase P (P-RNA) have been intensely studied and are currently best understood. Escherichia coli P-RNA is essential for the enzymatic activity in vivo and is the only subunit necessary for activity in vitro (Stark et al. 1978; Kole and Altman 1981; Guerrier-Takada et al. 1983). Comparisons of all known P-RNAs have revealed significant primary and secondary structure similarities, indicating that these molecules evolved from a com-

Reprint requests to: B. Franz Lang, Département de Biochimie, Université de Montréal, 2900 Boul. Edouard-Montpetit, Montréal, Québec, H3T 1J4, Canada; e-mail: Franz.Lang@Umontreal.ca; fax: (514) 343-2210.

Article and publication are at http://www.rnajournal.org/cgi/doi/ 10.1261/rna.5880403. mon ancestral RNA. The in vitro activity of P-RNAs in the absence of a protein component has been demonstrated in numerous instances (Guerrier-Takada et al. 1983; Gardiner et al. 1985; Wagner et al. 2001). Nevertheless, the single eubacterial protein component of RNase $\mathrm{P}$ (P-protein) is essential for the enzymatic activity in vivo. It has been suggested that the protein participates in formation of an active-site architecture, by interacting with the $5^{\prime}$ leader of tRNAs (Crary et al. 1998), and that it increases the catalytic activity of RNase P by acting as an electrostatic shield between the negatively charged P-RNA and tRNAs (GuerrierTakada et al. 1983; Gardiner et al. 1985; Christian et al. 2002). The P-protein also broadens the substrate specificity of RNase P, by enhancing its affinity for non-tRNA substrates. For example, 4.5 S RNA and C4 RNA precursors are processed more efficiently by a P-RNA/P-protein complex than by P-RNA alone (Peck-Miller and Altman 1991; Hartmann et al. 1995).

The P-RNA secondary structure model of Archaebacteria is strikingly similar to that of eubacteria, except for the lack of the P13, P14, and P18 helices (Brown and Haas 1995; Brown 1999). Archaeal P-RNAs were long thought to be 
inactive without their protein partner (see Brown and Haas 1995). However, the P-RNAs of Methanobacteria, Thermococci, and Halobacteria do have catalytic activity under extreme ionic conditions (Pannucci et al. 1999). In fact, deletion mutants show that the structural elements missing in archaeal P-RNAs are also dispensable for in vitro catalysis by the E. coli RNA molecule (Darr et al. 1992; Haas et al. 1994). Although archaebacterial P-RNA structures resemble those of eubacteria, the archaeal holoenzyme is much larger. It has at least four protein subunits that appear to be homologs of the eukaryotic P-proteins (Hall and Brown 2002).

Eukaryotic nuclear P-RNAs have been investigated in detail in ascomycete fungi and in animals. They have no catalytic activity in vitro and, as in archaebacteria, consist of an RNA subunit and several proteins, at least nine in yeast and 10 in human (Gopalan et al. 2002; Guerrier-Takada et al. 2002). A secondary structure model of the eukaryotic PRNA conforms convincingly to the bacterial consensus structure with only minor deviations (Chen and Pace 1997; Frank et al. 2000). In plants, RNase $P$ has been purified, and a P-RNA component has been suggested based on the sensitivity of the carrot RNase $\mathrm{P}$ activity to micrococcal nuclease treatment (Franklin et al. 1995). Although the nuclear RNase P from wheat is resistant to nuclease treatment, its density and its low isoelectric point also indicate the presence of a P-RNA subunit (Arends and Schön 1997). In fact, RNase P from rat liver (Jayanthi and Van Tuyle 1992) and the archaebacterium Sulfolobus solfataricus (Darr et al. 1990) resist micrococcal nuclease treatment but do contain a P-RNA subunit (Altman et al. 1993; Harris et al. 2001). This indicates that the RNA subunit is protected from digestion by $\mathrm{P}$-proteins.

Mitochondria and chloroplasts contain distinct, organelle-specific RNase P activities. The analysis of organellar P-RNAs has been complicated by the patchy occurrence of the $\operatorname{rnp} B$ gene, both in chloroplast and mitochondrial DNAs (mtDNAs). The chloroplast-encoded P-RNA of Cyanophora paradoxa folds into a Cyanobacteria-like secondary structure (in agreement with the cyanobacterial origin of chloroplasts) and is essential for RNase $\mathrm{P}$ activity (Baum et al. 1996; Pascual and Vioque 1999). Chloroplast DNA (cpDNA)encoded $r n p B$ genes have been found only in the green alga Nephroselmis olivacea (Turmel et al. 1999), the red algae Porphyra purpurea (Reith and Munholland 1995), and Cyanidium caldarium. We identified the latter, previously unrecognized $\operatorname{rnp} B$ gene, at positions 99,959-100,305 of GenBank record AF022186, (Glöckner et al. 2000). All other known cpDNAs do not seem to encode a P-RNA. A recent prediction of a maize chloroplast $r n p B$ gene (Collins et al. 2000) is based on rather weak secondary structure similarities to known homologs, does not consider otherwise highly conserved primary sequence motifs, and has not been confirmed experimentally. Inferences that do not take primary sequence conservation into account are compromised because $\mathrm{A}+\mathrm{T}$-rich chloroplast sequences can fit almost any given consensus structure and are, therefore, of little predictive value. Moreover, several biochemical studies indicate that chloroplast RNase P (cpRNase P) may not contain an organelle coded P-RNA. For instance, spinach cpRNase P activity resists micrococcal nuclease treatment and has physical properties consistent with the presence of a protein-only enzyme. These characteristics indicate that spinach cpRNase $P$ is indeed a protein-only enzyme (Thomas et al. 2000).

Mitochondrial RNase $\mathrm{P}$ activities have been studied in various yeasts (see below), the ascomycete fungus Aspergillus nidulans (Lee et al. 1996a), human (Doersen et al. 1985; Rossmanith and Karwan 1998; Puranam and Attardi 2001; Rossmanith and Potuschak 2001), Trypanosoma brucei (Salavati et al. 2001), potato (Marchfelder and Brennicke 1994), wheat (Hanic-Joyce and Gray 1990), and carrot (Franklin et al. 1995). The most detailed information on the biochemical and genetic properties of mitochondrial RNase $\mathrm{P}$ (mtP-RNA) is available for Saccharomyces cerevisiae. Its RNA subunit was first identified as a mitochondrially encoded molecule by analyzing yeast mitochondrial mutants deficient in mitochondrial tRNA processing and protein synthesis (Miller and Martin 1983; Underbrink-Lyon et al. 1983). The unusually large protein subunit has been shown to be nucleus-encoded (Morales et al. 1992; Dang and Martin 1993).

Additional $\operatorname{rnp} B$ genes have been identified by sequence similarity in mtDNAs of numerous budding yeasts ( $T$. glabrata, Clark-Walker et al. 1985; Saccharomycopsis fibuligera, Wise and Martin 1991a; Kluyveromyces lactis, Wilson et al. 1989; Saccharomyces exiguus, Wise and Martin 1991b; Saccharomyces douglasii; Ragnini et al. 1991; Saccharomyces chevalieri, Saccharomyces ellipsoideous, and Saccharomyces diastaticus, Sbisa et al. 1996; and Saccharomyces castellii, Petersen et al. 2002), the protist Reclinomonas americana (Lang et al. 1997), and the prasinophyte green alga N. olivacea (Turmel et al. 1999), but not in the mtDNAs of plants, animals, a great number of protists, or nonascomycete fungi (Lang et al. 1999). From an evolutionary standpoint, it is puzzling that the occurrence of mitochondrially encoded $r n p B$ genes is so patchy. Have these genes been lost from the mtDNAs of plants, animals, most fungi, and protists, or do we fail to identify them because they are so extremely derived? In fact, highly derived, extremely A+U-rich mtPRNAs are characteristic in yeast. Consequently, predictions of yeast mtP-RNA secondary structures are difficult, despite the availability of comparative data. In addition, the drastic size variations of these RNA molecules obscure the identification of RNA secondary structure elements (Wise and Martin 1991a). For example, the respective lengths of predicted mtP-RNAs are $423 \mathrm{nt}$ for S. cerevisiae (Stribinskis et al. 1996), 227 nt for Torulopsis glabrata (Shu et al. 1991), and as short as $140 \mathrm{nt}$ for Saccharomycopsis fibuligera (Wise and Martin 1991a).

The mitochondrially encoded mtP-RNA of the protist Reclinomonas americana was the first identified to contain 
all structural elements defined in the eubacterial P-RNA consensus structure (Lang et al. 1997). Its features served as a hallmark for reanalyzing the mtP-RNA secondary structure of $A$. nidulans. This analysis reveals a secondary structure that is substantially more similar to both the $R e$ clinomonas mitochondrial and to the eubacterial consensus (Martin and Lang 1997) than to the previously published model (Lee et al. 1996b). In this article, we present the results of our ongoing efforts to identify ascomycete $r n p B$ genes, and to infer their RNA secondary structures by comparative phylogenetic modeling. We provide evidence that the mitochondrial $r m p B$ genes have been lost several times independently in fungi.

\section{RESULTS}

\section{Search for ascomycete mitochondrial $r n p B$ genes}

To identify previously unrecognized, possibly highly derived $r m p B$ genes in fungal mtDNAs, we used two equally productive in silico procedures. The more straightforward of the two was based on sequence pattern recognition (PERL regular expression matching), including the most conserved rnpB sequence motifs CRI and CRV (GGAAAGTC...50500 nt...ACANAANNNNGCTTAT; Fig. 1; Chen and Pace 1997). Potential deviations from the consensus sequence were explored by gradually changing the primary sequence motifs, and subsequently, all matches were validated by folding of the highly conserved P4 helix (Fig. 2A,B). Only those candidate $\operatorname{rnp} B$ sequences that fall into a noncoding region of a given mtDNA were further investigated. The second approach used the dedicated pattern matching tool, RNAMOT (Laferrière et al. 1994), which searches for both sequence similarity and RNA secondary structure folding. Because this program does not allow errors,

\begin{tabular}{|c|c|c|}
\hline Species & CR IV & CR V \\
\hline. $\operatorname{coll}$ & GAGGAAAGUCCOSOC $\{250)$ CUAGAUTAADEACU & (6) GACAQAA- -6 \\
\hline owar & AACUCCGSAC (201) CUAGAUAAAUAACU ( & \\
\hline - & IAGGAAA GUCUOSAC $\{193)$ UCAGACAAAUAGAC ( & (28) $\mathrm{CA}$ \\
\hline *. 0 & AAGCAAAGUCUGSOC (21日) UCAGAUAAAOGAGC & $(29) \mathrm{OM}$ \\
\hline a. 1 & UUAGAAUUADAAAA & AA \\
\hline r. & 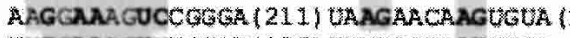 & $\mathbf{A}$ \\
\hline s.p. & WUUUACUAAUUUCA & $\mathrm{UAU}$ \\
\hline$\$ .0$ & AAGUUUOCAA (91) UUUAAGUAAUUUCA & UAd \\
\hline & $\mathrm{UAC}$ & AA \\
\hline$s$. & NAAUCAUAUA (379) UAAGUUAUAUAAAA & CACAA-CUA: \\
\hline & AAGUCAUAAU (207) AUAGUUAUAOAUCU & CASAA-ATAL \\
\hline & AGUCAUAAA $\{150)$ AUAGUUAUAUAAUA & (0) UACAUAA-AUAA \\
\hline bul: & UAGGAAAGUCAUAAA & (81) AACUAAA-WUATECUUAU \\
\hline & GATU (100) AUUG: & AtracuUad \\
\hline der & AAGGAAAGUUAUANU (72) UAAGUUAAAUAADA & (0) ANCUAAAAATAAGCUUAV \\
\hline
\end{tabular}

FIGURE 1. Alignment of the universally conserved regions (CRs) I, IV, and V. CRs of the universally conserved nucleotides are in bold, following the analysis by Chen and Pace 1997. Shaded nucleotides are conserved at $>75 \%$, in E. coli, $R$. prowazekii, and mitochondrial PRNAs. The numbers between brackets indicate the number of nucleotides that separate the conserved regions. possible deviations from the consensus sequence were also explored by systematic changes of the sequence descriptor. All publicly available fungal mtDNAs were analyzed accordingly.

Significant CRI and CRV matches turned up for the three known $r p$ B genes in S. cerevisiae (Miller and Martin 1983), S. castellii (Petersen et al. 2002), and A. nidulans (Lee et al. 1996a), and four new candidates emerged in Pichia canadensis (Sekito et al. 1995), Schizosaccharomyces pombe (Lang et al. 1983), Schizosaccharomyces octosporus (Bullerwell et al. 2003b), and Taphrina deformans, a fungus classified within Archiascomycota (or Taphrinomycetales, according to the National Center for Biotechnology Information [NCBI] nomenclature). Sequence alignments are shown in Figure 1. However, we failed to detect mitochondrial $\operatorname{rnp} B$ genes in six other ascomycetes and in all basidiomycete and chytridiomycete fungi for which complete, or near-complete, mtDNA sequences are available (Table 1), even at search pattern stringency close to background levels.

\section{Modeling of fungal mtP-RNA secondary structures}

Fungal mitochondrial $r n p B$ genes, including those newly identified, vary considerably in size and primary sequence. In addition, most are exceedingly rich in $\mathrm{A}$ and $\mathrm{T}$, which makes RNA modeling an intricate task. It requires substantial comparative sequence information to determine a biologically meaningful solution among the many alternative structure predictions. To deal with the dilemma that in the absence of primary sequence conservation, A+T-rich sequences can be fitted to any given consensus structure, we have based our predictions on three criteria, namely, similarity to (1) the bacterial minimum consensus structure, (2) the universally conserved motifs in bacterial P-RNAs, and

(3) the secondary structure models of $R$. americana and $A$. nidulans mtP-RNA.

From studies of eubacterial P-RNAs, it is known that the P1 and P4 helices are the functionally most important regions of this RNA molecule (i.e., most sensitive to mutations; see the bacterial consensus structure in Fig. 2A; Schlegel et al. 1994). This is reflected by the presence of the highly conserved mitochondrial CRI and CRV motifs in all mitochondrial $r n p B$ sequences (Fig. 1), which together fold into a $\mathrm{P} 4$ helix. In addition, here we demonstrate for the first time that $\mathrm{P} 1$ is also conserved in all known mtP-RNAs (Fig. 2A,B), with the possible exception of $K$. lactis, as discussed below. However, several other helical regions that characterize the bacterial consensus structure are lost in mtP-RNAs, as outlined below. 


\section{Budding yeast mtP-RNAs}

To define a consensus RNA secondary structure model for budding yeast mtP-RNAs, we performed a comparative analysis of all available sequences, except those from $S$. chevalieri, S. douglasii, S. ellipsoideous, and S. diastaticus, because they are almost identical to the $S$. cerevisiae sequence.

In addition to the CRI and CRV motifs, we found a potential, previously unrecognized CRIV motif (AGNNNNAU; Figs. 1, 2A). Identification of this motif was based on the assumption that a P2 helix would be absent in
A
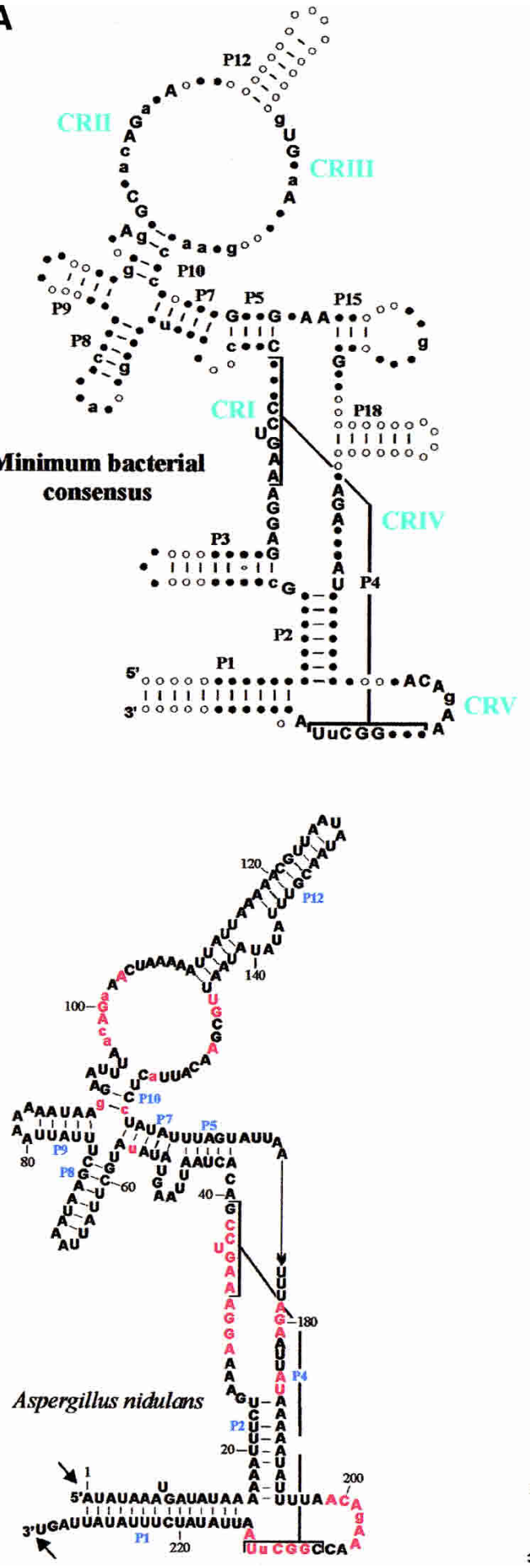
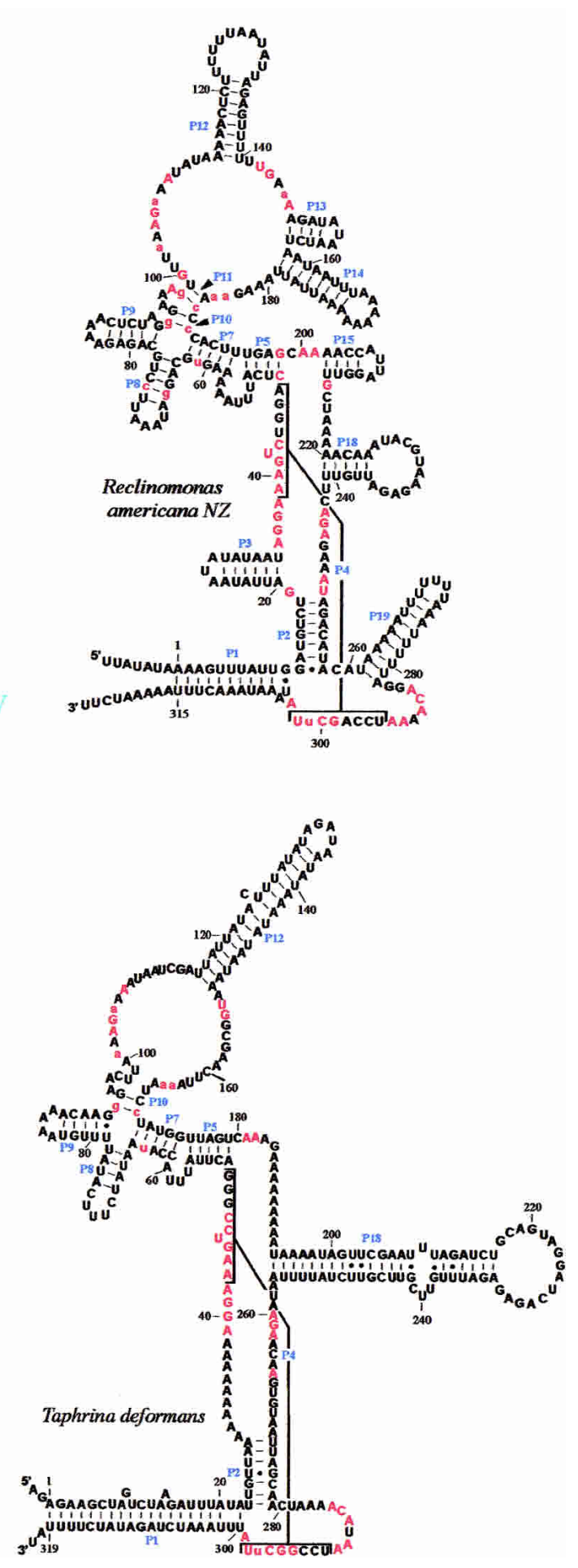

FIGURE 2. (Continued on next page) 
all yeast mtP-RNAs, such that it would be positioned directly adjacent to the $\mathrm{CRV}$ motif. By using these criteria, CRIV motifs were found in all but the S. fibuligera and $K$. lactis $r m p B$ sequences (Figs. 1, 2B). In addition, in K. lactis the P1 helix is formed by only few base pairs (labeled "P1?" in Fig. 2B), the CRI motif has a deletion of a universally conserved $\mathrm{A}$, and $\mathrm{CRV}$ has a $\mathrm{U}$ in the third position that is otherwise a $\mathrm{C}$ (Fig. 1). We confirmed the unconventional deletion of an A in the $K$. lactis CRI motif, by resequencing the clone containing the $r m p B$ gene. Although a transcript of
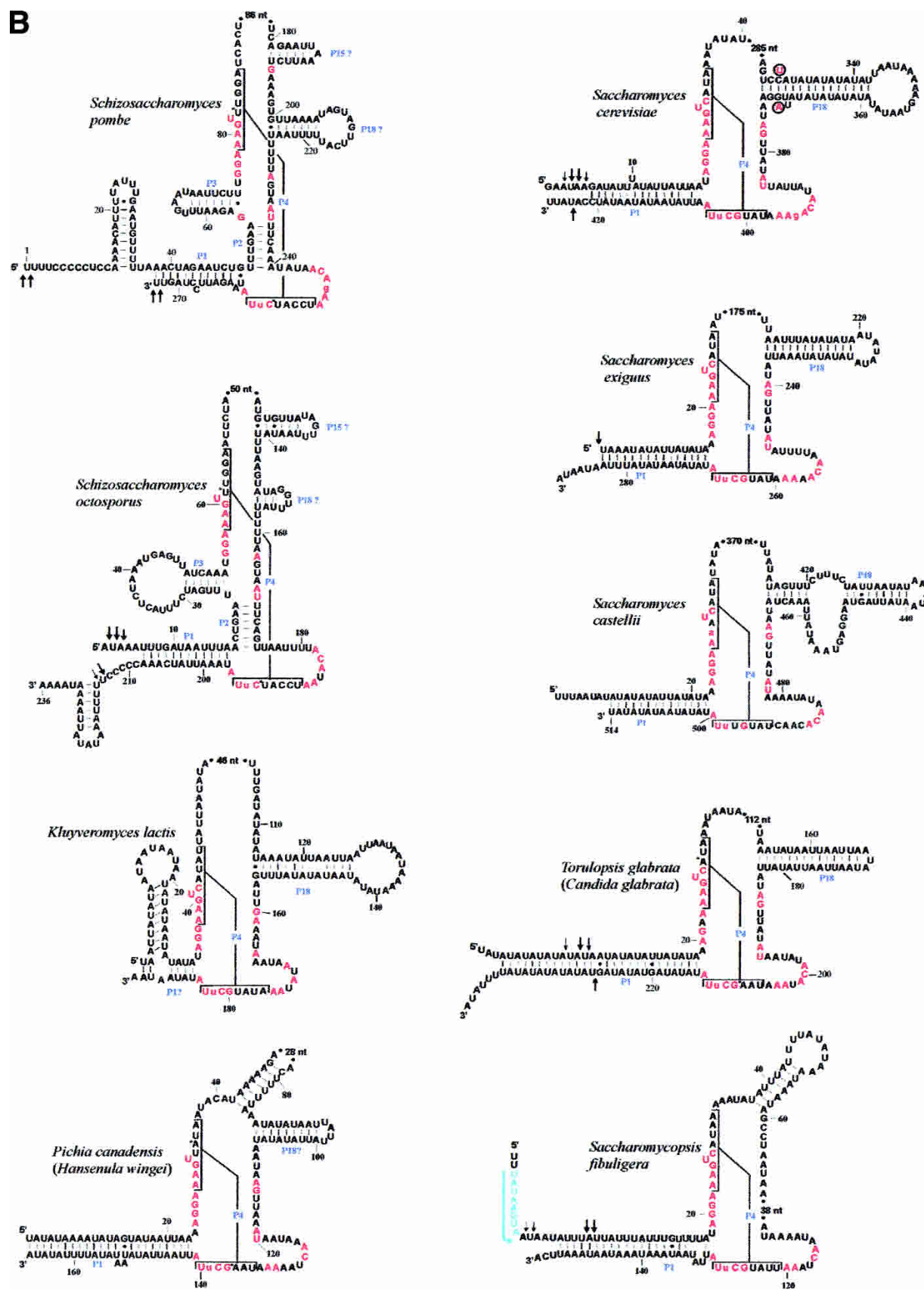

FIGURE 2. Minimum bacterial P-RNA consensus and mtP-RNA secondary structure models of R. americana and ascomycete fungi. (A) Positions in red are invariant in the minimum bacterial consensus; uppercase letters in the mtP-RNAs indicate $100 \%$, lowercase letters at least $90 \%$, conservation of the minimum bacterial consensus sequence. The conserved motifs CRI through CRV are indicated in blue. The arrows indicate experimentally determined RNA extremities; arrow thickness is proportional to the percentage of molecules ending at this position. $(B)$ mtP-RNA secondary structures from nine additional ascomycetes. In the S. cerevisiae structure, nucleotides that co-vary with the Saccharomyces douglasii sequence are in red circled letters. A putative promoter in S. fibuligera is highlighted in blue. Asterisks next to nucleotides in the P4 of S. pombe, S. octosporus, C. glabrata, and P. canadensis indicate mispairs in these helices. Note that the Candida structure P1 helix can be further extended by 9 to $12 \mathrm{bp}$ from its mature ends. It is possible that the noncanonical A-G pair adjacent to the RNA processing sites in this mtP-RNA serves as a signal for RNA maturation. 
TABLE 1. Occurrence and features of $r n p B$ in complete fungal mtDNA sequences

\begin{tabular}{|c|c|c|c|c|c|c|c|}
\hline Organismal group & $\begin{array}{c}\text { mtDNA- } \\
\text { encoded } r n p B^{a}\end{array}$ & $\mathrm{P} 2$ & P3 & P15 & P18 & $\begin{array}{l}\mathrm{P} 5,7,8, \\
9,10,12\end{array}$ & Accession \# \\
\hline \multicolumn{8}{|l|}{ Ascomycota (Euascomycota) } \\
\hline Aspergillus nidulans & $\mathbf{\square}$ & $\mathbf{\square}$ & $\square$ & $\square$ & $\square$ & $\mathbf{\square}$ & $\mathrm{b}$ \\
\hline Hypocrea jecorina & $\square$ & & & & & & NC_003388 \\
\hline Neurospora crassa & $\square$ & & & & & & $\mathrm{c}$ \\
\hline Podospora anserina & $\square$ & & & & & & NC_001320 \\
\hline Verticillium lecanii & $\square$ & & & & & & AF487277 \\
\hline \multicolumn{8}{|l|}{ Ascomycota (Hemiascomycota) } \\
\hline Candida albicans & $\square$ & & & & & & NC_002653 \\
\hline Candida glabrata & $\bar{\square}$ & $\square$ & $\square$ & $\square$ & $\mathbf{\square}$ & $\square$ & AJ511533 \\
\hline Pichia canadensis & $\overline{\mathbf{n}}$ & $\square$ & $\square$ & $\square$ & $\overline{\mathbf{a}}$ & $\square$ & NC_001762 \\
\hline Saccharomyces castellii & $\bar{\square}$ & $\square$ & $\square$ & $\square$ & $\overline{\mathbf{a}}$ & $\square$ & AF437291 \\
\hline Saccharomyces cerevisiae & $\overline{\mathbf{\square}}$ & $\square$ & $\square$ & $\square$ & $\overline{\mathbf{\square}}$ & $\square$ & NC_001224 \\
\hline Yarrowia lipolytica & $\bar{\square}$ & & & & & & NC_002659 \\
\hline \multicolumn{8}{|l|}{ Ascomycota (others) } \\
\hline Schizosaccharomyces japonicus & $\square$ & & & & & & NC_004332 \\
\hline Schizosaccharomyces octosporus & $\bar{\square}$ & $\mathbf{\square}$ & $\mathbf{\square}$ & $\mathbf{\square}$ & $\mathbf{\square}$ & $\square$ & AF275271 \\
\hline Schizosaccharomyces pombe & $\overline{\mathbf{\square}}$ & $\overline{\mathbf{a}}$ & $\overline{\mathbf{n}}$ & $\overline{\mathbf{a}}$ & $\bar{\square}$ & $\square$ & NC_001326 \\
\hline Taphrina deformans & $\overline{\mathbf{\square}}$ & $\overline{\mathbf{a}}$ & $\square$ & $\square$ & $\bar{\square}$ & - & AY $262107^{d}$ \\
\hline Basidiomycota $^{e}$ & $\square$ & & & & & & \\
\hline Chytridiomycota $^{\mathrm{e}}$ & $\square$ & & & & & & \\
\hline
\end{tabular}

Filled and empty squares stand for presence or absence of the gene or helices, respectively.

${ }^{\mathrm{a} A l l} \mathrm{mtP}-\mathrm{RNAs}$ contain $\mathrm{P} 1$ and $\mathrm{P} 4$.

bThe A. nidulans sequence is almost complete: ODAS1, CAA33481, AAA99207, AAA31737, CAA25707, AAA31736, CAA23994, X15442, P15956, CAA23995, CAA33116, X00790, X15441, X06960, J01387, and X01507.

${ }^{c}$ Completed at Whitehead Institute, currently available at http://pages.slu.edu/faculty/kennellj/genbank.html.

dThe GenBank record documents the $r n p B$ sequence, the complete sequence is unpublished.

'Mitochondrial rnpB genes have not been identified in basidiomycete (Cantharellus cibarius, unpubl.; Cryptococcus neoformans, NC00_4336;

Microbotryum violaceum, unpubl.; Schizophyllum commune, NC_003049) or chytridiomycete fungi (Allomyces macrogynus, NC_001715;

Harpochytrium94, AY182005; Harpochytrium105, AY182006; Hyaloraphidium curvatum, NC_003048).

the expected size is found in K. lactis mitochondria (Wilson et al. 1989), the high incidence of noncanonical features raises the question whether or not $\operatorname{mp} B$ codes for a functional mtP-RNA.

Further comparative analysis revealed another conserved base pairing, P18 (Fig. 2A), in the five phylogenetically closely related organisms S. cerevisiae, S. castellii, T. glabrata, S. exiguus, and K. lactis (Fig. 2B). These helical regions start at the same position as P18 of R. americana and as P18 in the bacterial minimum consensus model, $2 \mathrm{nt}$ upstream of the CRIV motif (Fig. 1B). Additional support for this P18 helix comes from a compensatory exchange of a base pair (G-C to A-U) between the S. cerevisiae and S. douglasii mtP-RNAs (see the circled nucleotides of the $S$. cerevisiae structure in Fig. 2B). In $P$. canadensis, a P18 pairing is possible (labeled "P18?" in Fig. 2B); however, it is not located at the same position relative to the CRIV motif. Finally, we did not detect a CRIV motif or a $\mathrm{P} 18$ pairing in the S. fibuligera mtP-RNA.

\section{Fission yeasts}

The S. pombe rnpB gene was only identified recently, although the complete sequence of mtDNA has been available for more than a decade. Differences in both the CRI and CRV motifs, relative to the consensus (Fig. 1), made it difficult to recognize this gene. After identifying potential CRI, CRIV, and CRV motifs in an intergenic region of the S. pombe mtDNA, we confirmed the presence of an $r n p B$ homolog in $S$. octosporus at the same location in the mtDNA, flanked by the same tRNA genes, $\operatorname{trn} A$ and $\operatorname{trn} G$.

The comparative structural modeling of the two Schizosaccharomyces sequences reveals not only the presence of $\mathrm{P} 1$ and $\mathrm{P} 4$, as in budding yeasts, but also $\mathrm{P} 2$ and $\mathrm{P} 3$ pairings that distinguish them from most other fungal RNA structures (Fig. 2B). Moreover, we identified potential P15 and $\mathrm{P} 18$ pairings. However, only the $S$. pombe $\mathrm{P} 18$ is located at the same distance from CRIV as in other species, and the potential S. octosporus P18 helix would be only $3 \mathrm{bp}$ long (Fig. 2B). The central sequence of $r n p B$ contains three motifs that are identical in the fission yeasts $(4,6$, and $9 \mathrm{nt}$ long; Fig. 2B), but without similarity to the bacterial consensus.

T. deformans has been grouped together with Schizosaccharomyces species in phylogenetic analyses (termed archiascomyetes, Nishida and Sugiyama 1993; for an alternative view, see Bullerwell et al. 2003b; Leigh et al. 2003), but the mtP-RNA secondary structure of $T$. deformans exhibits 
striking similarity only to the euascomyete A. nidulans (Fig. 2B). The only principal structural difference is the extra P18 pairing in $T$. deformans.

\section{Mapping of mtP-RNAs}

As indicated in the bacterial consensus structure (Fig. 2A), the $5^{\prime}$ and $3^{\prime}$ extremities of most mapped P-RNA molecules are directly adjacent, or at least close to, the P1 helix of P-RNAs. We show here by primer extension that the putative $S$. fibuligera $\mathrm{mtP}-\mathrm{RNA}$ is processed at its $5^{\prime}$ end to an RNA molecule with a perfect terminal P1 helix (Figs. 2B, 3). In $S$. pombe and $S$. octosporus, the $5^{\prime}$ ends were initially mapped by primer extension experiments (Fig. 3) and confirmed by RT-PCR of the circularized RNAs and sequencing of the PCR product. The sequencing results confirmed the primer extension results shown in Figure $2 \mathrm{~B}$ and revealed that there is only a marginal heterogeneity of mtP-RNA extremities.

Results further show that the $3^{\prime}$ end of $S$. pombe and the $5^{\prime}$ end of $S$. octosporus mtP-RNAs correspond well to the predicted RNA structure model (Fig. 2B). The $5^{\prime}$ end of $S$. pombe and the $3^{\prime}$ end of $S$. octosporus are somewhat longer than expected, at sequence motifs rich in cytidines and uridines. Similar motifs are present at most $3^{\prime}$ ends of mitochondrial protein-coding genes in S. pombe, S. octosporus (Bullerwell et al. 2003b), and several zygomycete and basidiomycete mitochondrial genomes (B.F. Lang, unpubl.). These sequence motifs may be RNA processing signals (Lang et al. 1983; Trinkl et al. 1989), and protect the RNA extremities against further exonuclease digestion.

\section{DISCUSSION}

\section{Highly reduced mtP-RNA structures in fungi}

We report here the identification of four previously undetected mitochondrial $r n p B$ genes in ascomycetes. Comparative RNA secondary structure modeling of previously and newly discovered sequences allowed us to establish a minimum consensus secondary structure for fungal mtP-RNAs (for a complete collection of mtP-RNA structures, see http://megasun.bch.umontreal.ca/People/lang/rnpB/). The fungal mitochondrial consensus includes only two out of the five conserved motifs (CRI and CRV) and two out of 11 conserved helices (P1 and P4; Fig. 2A) found in the mini-
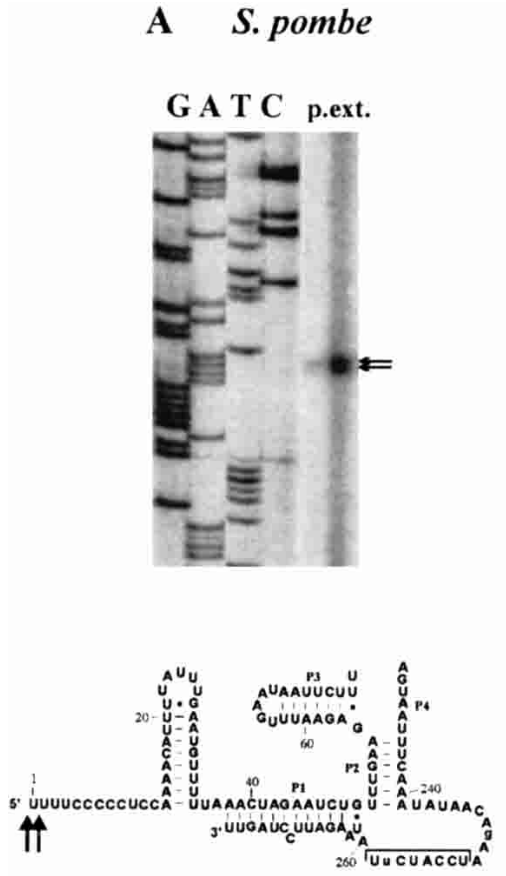

B S. octosporus

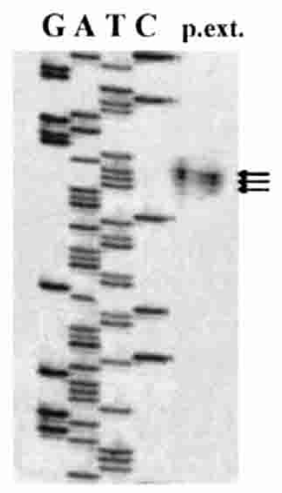

C S. fibuligera
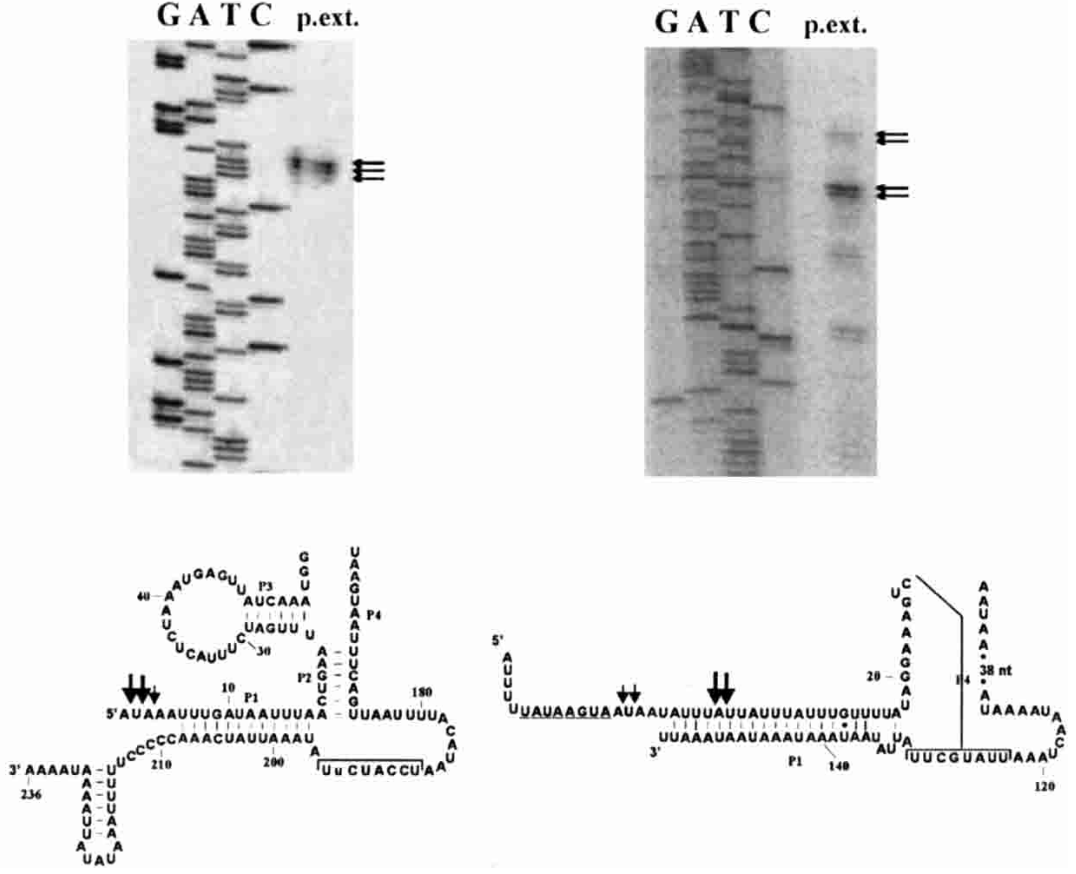

FIGURE 3. RNA mapping of $S$. pombe, S. octosporus, and S. fibuligera mtP-RNAs. (A) S. pombe primer extension experiment. The bottom part of the figure shows the partial, corresponding region of the mtP-RNA structure. The main bands are consistent with sequencing of RT-PCR product of in vitro circularized P-RNA. The thickness of the arrows is proportional to the proportion of RNA extremities of the RT-PCR experiment. (B) S. octosporus primer extension experiment. The main bands are consistent with sequencing of RT-PCR product of in vitro circularized P-RNA. The thickness of the arrows is proportional to the proportion of RNA extremities of the RT-PCR experiment. (C) Primer extension for $S$. fibuligera mtP-RNA. The weak upper signal matches the transcription initiation site at the potential promoter sequence (underlined). The strongest signal corresponds to the mature end of the mtP-RNA. 
mum bacterial consensus structure. The presence of additional conserved structural elements appears to tightly correlate with the phylogenetic relatedness. For example, P2, P3, P15, and P18 are found in the two Schizosaccharomyces species, but only P18 is found in most (but not all) budding yeasts (Table 1). Accordingly, the occurrence of P2, P5, P7-10, and P12 in both T. deformans and A. nidulans possibly indicates that $T$. deformans is an ancestral fungus that branches at the base of the ascomycetes. Although it has been proposed to be related to Schizosaccharomyces species based on rRNA phylogenies (Nishida and Sugiyama 1993), it does not appear to be related based on either mtP-RNA structure or from mitochondrial protein sequences (Leigh et al. 2003).

The reduction of the structural complexity of mtP-RNAs is more extensive in fungal mitochondria than in nuclear (Frank et al. 2000) and archaeal P-RNAs (Harris et al. 2001). It is likely compensated by increase in size and/or number of P-proteins (e.g., the large size of the mitochondrial P-protein in S. cerevisiae; Morales et al. 1992; Dang and Martin 1993) and the possibility of multiple mitochondrial P-proteins in A. nidulans (Lee et al. 1996b). An investigation of fungal mitochondrial P-proteins and of native mtP-RNA enzymes could be useful in shedding light on the principles related to the replacement of RNA by protein structure. Despite the substantial loss of structural complexity, the fungal mtP-RNAs are likely to be the catalytic component of RNase P. Deletion analysis shows that bacterial P1 and P4 elements are intimately involved in catalytic function (Guerrier-Takada and Altman 1992; Schlegl et al. 1994). This hypothesis is also supported by genetic and biochemical studies in $S$. cerevisiae and $A$. nidulans, showing that the RNA subunit is essential for mtP-RNA activity (Miller and Martin 1983; Underbrink-Lyon et al. 1983; Lee et al. 1996a).

\section{Processing of fungal mtP-RNAs}

The processing of precursor molecules of structural RNAs usually depends on highly specific biochemical activities that recognize RNA structure. This prompted the question whether this also applies to mtP-RNAs. The RNA mapping data presented here indicate two types of mtP-RNA processing. First, in S. pombe, S. octosporus, and several budding yeasts (including $S$. cerevisiae and C. glabrata; Shu and Martin 1991), rnpB genes are flanked by tRNA genes. The removal of tRNA sequences from the RNA precursor directly liberates mature mtP-RNA molecules in some instances (e.g., as shown here in S. pombe, Fig. 2B; and as predicted in $P$. canadensis, $S$. exiguus, and $K$. lactis from the positioning of the postulated processing sites). It follows the tRNA "punctuation model" first described as the key principle of human mitochondrial RNA processing (Ojala et al. 1980), as well as in S. pombe and a few other fungi (Paquin et al. 1997). Note that RNA processing by tRNA punctua- tion is not a general principle in budding yeast mitochondria, although applied in maturation of the mtP-RNA. In fact, there is a high overall incidence of mitochondrial $r m p B$ genes that are flanked on both sides, or at least one side (and then most frequently at the $3^{\prime}$ end), by tRNA genes. This implies that in numerous instances, RNase P itself has a defining role in $3^{\prime}$ processing of its RNA subunit. Second, in some cases, $3^{\prime}$ and $5^{\prime}$ end processing occurs subsequent to tRNA removal. For example, processing of $3^{\prime}$ ends of transcripts containing cytidine-uridine-rich motifs occurs in S. octosporus (Fig. 2B). The primary transcript in S. cerevisiae includes tRNA ${ }^{\text {Metf }}$, mt-PRNA (also called Rpm1r), and $t R N A^{\text {Pro }}$. The $t R N A s$ are first separated from the mtPRNA precursor, and secondary maturation occurs at both P-RNA ends (Stribinskis et al. 1996), with the possible involvement of the mitochondrial P-protein (Stribinskis et al. 2001). The $r n p B$ gene of $S$. fibuligera is flanked only downstream by tRNA ${ }^{\text {Pro }}$, but upstream by a protein coding gene ( $\operatorname{cox} 2$ ). The sequence immediately upstream of $r n p B$ contains a conserved octanucleotide promoter motif (TATAAGTA; Fig. 2) that serves as a promoter in $S$. cerevisiae. Our primer extension analysis in $S$. fibuligera indicates that $\operatorname{rnpB}$ is indeed transcribed from this putative promoter (Fig. 3), so that starting transcription close to the $5^{\prime}$ end is yet another potential mechanism leading to the definition of mtP-RNA extremities. The same mechanism potentially applies to $S$. cerevisiae, as an alternative pathway to maturation by tRNA punctuation (Biswas 1996). Finally, in A. nidulans and T. deformans none of the previously discussed mechanisms seem to apply.

\section{Mitochondrial $r n p B$ genes in other fungi, plants, or protists?}

We failed to detect mitochondrial $r n p B$ genes in 18 out of 26 complete fungal mtDNAs. These negative matches included all studied basidiomycete and chytridiomycete fungi, four euascomycete fungi, two budding yeasts, and one fission yeast (Table 1). In these species, a mitochondrial $r n p B$ either migrated to the nucleus, or had its function replaced by a nuclear encoded gene, or, less likely, diverged to a degree that it is no longer recognizable. There is evidence to indicate that $r n p B$ is indeed absent from most of the abovelisted mtDNAs. In the chytridiomycete fungi Harpochytrium94 and Harpochytrium105 (Bullerwell et al. 2003a), intragenic regions are either too short or filled with repeats so there is no space to fit an $r m p B$ gene. The chytridiomycte fungus, A. macrogynus, has the most ancestral (underived) mtDNA sequence among all known fungi, with respect to both gene content and gene sequence similarity. Therefore, although one might expect that $A$. macrogynus would have an easily identifiable, eubacterial-like mitochondrial $r n p B$, we were unable to locate even a highly derived version of this gene. S. pombe and S. octosporus mtDNAs contain $r n p B$ sequences that are highly similar and easily identified by sequence comparisons. Yet, there is no significant match 
with a third fission yeast mtDNA, that of S. japonicus. $P$. anserina, $H$. jecorina, and Verticillium lecanii are closely related to A. nidulans. A. nidulans is the only one of the four that has a eubacteria-like $\operatorname{rnp} B$ sequence. Otherwise, their mitochondrial gene content is identical, which indicates that none of these four species has undergone accelerated evolution. Evidently, sequences from more deeply diverging members of the euascomycetes need to be investigated to support the idea that loss of mitochondrial $r n p B$ is typical for this fungal group.

This widespread loss raises the question of how the RNase $\mathrm{P}$ function is provided in the absence of a mitochondrial encoded $r n p B$ gene. One possibility is that a proteinonly enzyme, coded by nuclear gene(s) and imported into the organelle, is responsible for $5^{\prime}$ processing of precursor tRNAs, a situation postulated for spinach chloroplast (Thomas et al. 2000). An alternate possibility is that an RNA is required for catalysis but that it is encoded in the nucleus and imported into mitochondria to function. Biochemical characterization of the RNase $\mathrm{P}$ activity isolated from mitochondria lacking an endogenous $r n p B$ will be necessary to differentiate between these possibilities. Such studies have been undertaken for human mtP-RNA, but there is an unresolved debate whether or not the absence of mitochondrially encoded $r n p B$ is compensated by the nuclear P-RNA, or by a protein-only enzyme (Rossmanith and Karwan 1998; Puranam and Attardi 2001; Rossmanith and Potuschak 2001).

\section{MATERIALS AND METHODS}

\section{DNA and RNA extraction, PCR, and sequencing}

S. pombe strain ade7-50h- (kindly provided by U. Leupold, University of Bern, Switzerland) S. octosporus (ATCC 2479), and T. deformans (NRRL T-857) were grown in 1\% yeast extract plus 3\% glycerol liquid medium. For mitochondrial DNA and RNA extractions, cells were broken mechanically, and a mitochondrial fraction was isolated by differential centrifugation (Lang et al. 1977). This fraction was lysed in the presence of $1 \%$ SDS and $100 \mu \mathrm{g} / \mathrm{mL}$ proteinase $\mathrm{K}$ for $1 \mathrm{~h}$ at $37^{\circ} \mathrm{C}$, and after phenol-chloroform extraction, the nucleic acids were precipitated with ethanol. For RNA extractions of Schizosaccharomyces strains, the cell walls were digested with lytic enzymes from Trichoderma harzianum (Sigma L-2265), and mitochondria were purified by differential centrifugation. The mitochondrial fraction was solubilized in the presence of $1 \%$ SDS and $100 \mu \mathrm{g} / \mathrm{mL}$ proteinase $\mathrm{K}$ for $1 \mathrm{~h}$ at $37^{\circ} \mathrm{C}$. After a phenol-chloroform extraction, the high-molecular-weight RNA fraction was precipitated with $2 \mathrm{M} \mathrm{LiCl}$, redissolved in RNase-free water, and ethanol-precipitated.

\section{Primer extension}

Primer extensions were performed with primers 5 '-CCCTCT TGGGTTTCTTTTTTA-3' (S. pombe) and 5'-GATGGATTATG TAAAATTAACTG-3' (S. octosporus). The primers were labeled at the $5^{\prime}$ end with $\gamma$-P32 ATP and T4 polynucleotide kinase (Boehringer). The mitochondrial RNA was incubated for $30 \mathrm{~min}$ at $37^{\circ} \mathrm{C}$ in the presence of the respective primers, dNTPs, AMV buffer (Boehringer), and AMV reverse transcriptase (Boehringer 1495062). The resulting product was ethanol-precipitated and loaded on a high resolution sequencing gel (see above). The DNA sequencing ladder that served as a size marker was produced with the same primer from a DNA template containing the $r m p B$ region from the organism being examined.

\section{RNA ligation and RT-PCR}

RNA ligation of mtP-RNAs, followed by RT-PCR amplification, was performed to determine precise $5^{\prime}$ and $3^{\prime}$ end(s). The protocol was essentially the same used to circularize tRNAs (Yokobori and Pääbo 1995), except that $\sim 10 \mu \mathrm{g}$ of RNA was used as starting material. The primers used for RT-PCR were $5^{\prime}$-CCCTCTTG GGTTTCTTTTTTA-3' and 5'-TTTTAGTAATTTCAAATATAA CAG-3' for $S$. pombe, and 5'-TCCAAACTTTCCATTTGATAAC$3^{\prime}$ and 5'-CAGTTAATTTTACATAATCCATC-3' for S. octosporus.

\section{ACKNOWLEDGMENTS}

We thank G. Burger and C. Bullerwell for comments on the manuscript, Wang Zhang for participation in DNA sequencing, Marlene Steffen for technical assistance, and H. Fukuhara (Orsay, France) for sharing information on $K$. lactis $r p p B$ and providing a clone carrying its sequence. This project was supported by operating grants from the Canadian Institute for Health Research (CIHR) to B.F.L. and the National Institutes of Health (NCM). Salary and interaction support (to B.F.L.) from the Canadian Institute for Advanced Research is gratefully acknowledged.

The publication costs of this article were defrayed in part by payment of page charges. This article must therefore be hereby marked "advertisement" in accordance with 18 USC section 1734 solely to indicate this fact.

Received May 15, 2003; accepted June 18, 2003.

\section{REFERENCES}

Altman, S., Wesolowski, D., and Puranam, P.S. 1993. Nucleotide sequences of the RNA subunit of RNase P from several mammals. Genomics 18: 418-422.

Arends, S. and Schön, A. 1997. Partial purification and characterization of nuclear ribonuclease P from wheat. Eur. J. Biochem. 244: 635-645.

Baum, M., Cordier, A., and Schön, A. 1996. RNase P from a photosynthetic organelle contains an RNA homologous to the cyanobacterial counterpart. J. Mol. Biol. 257: 43-52.

Biswas, T.K. 1996. Expression of the mitochondrial RNase P RNA subunit-encoding gene from a variant promoter sequence in Saccharomyces cerevisiae. Gene 170: 23-30.

Brown, J.W. 1999. The Ribonuclease P Database. Nucleic Acids Res. 27: 314

Brown, J.W. and Haas, E.S. 1995. Ribonuclease P structure and function in Archaea. Mol. Biol. Rep. 22: 131-134.

Bullerwell, C.E., Forget, L., and Lang, B.F. 2003a. Evolution of monoblepharidalean fungi based on complete mitochondrial genome sequences. Nucleic Acids Res. 31: 1614-1623. 
Bullerwell, C.E., Leigh, J., Forget, L., and Lang, B.F. 2003b. A comparison of three fission yeast mitochondrial genomes. Nucleic Acids Res. 31: 759-768.

Chen, J.L. and Pace, N.R. 1997. Identification of the universally conserved core of ribonuclease P RNA. RNA 3: 557-560.

Christian, E.L., Zahler, N.H., Kaye, N.M., and Harris, M.E. 2002. Analysis of substrate recognition by the ribonucleoprotein endonuclease RNase P. Methods 28: 307-322.

Clark-Walker, G.D., McArthur, C.R., and Sriprakash, K.S., 1985. Location of transcriptional control signals and transfer RNA sequences in Torulopsis glabrata mitochondrial DNA. EMBO J. 4: 465-473.

Collins, L.J., Moulton, V., and Penny, D. 2000. Use of RNA secondary structure for studying the evolution of RNase P and RNase MRP. J. Mol. Evol. 51: 194-204.

Crary, S.M., Niranjanakumari, S., and Fierke, C.A. 1998. The protein component of Bacillus subtilis ribonuclease $\mathrm{P}$ increases catalytic efficiency by enhancing interactions with the $5^{\prime}$ leader sequence of pre-tRNAAsp. Biochemistry 37: 9409-9416.

Dang, Y.L. and Martin, N.C. 1993. Yeast mitochondrial RNase P sequence of the RPM2 gene and demonstration that its product is a protein subunit of the enzyme. J. Biol. Chem. 269: 1979119796.

Darr, S.C., Pace, B., and Pace, N.R. 1990. Characterization of ribonuclease P from the archaebacterium Sulfolobus solfataricus. J. Biol. Chem. 265: 12927-12932.

Darr, S.C., Zito, K., Smith, D., and Pace, N.R. 1992. Contributions of phylogenetically variable structural elements to the function of the ribozyme ribonuclease P. Biochemistry 31: 328-333.

Doersen, C.J., Guerrier-Takada, C., Altman, S., and Attardi, G. 1985. Characterization of an RNase P activity from Hela cell mitochondria: Comparison with the cytosol RNase P activity. J. Biol. Chem. 260: 5942-5949.

Frank, D.N., Adamidi, C., Ehringer, M.A., Pitulle, C., and Pace, N.R. 2000. Phylogenetic-comparative analysis of the eukaryal ribonuclease P RNA. RNA 6: 1895-1904.

Franklin, S.E., Zwick, M.G., and Johnson, J.D. 1995. Characterization and partial purification of two pre-tRNA $5^{\prime}$-processing activities from Daucus carrota (carrot) suspension cells. Plant J. 7: 553-563.

Gardiner, K.J., Marsh, T.L., and Pace, N.R. 1985. Ion dependence of the Bacillus subtilis RNase P reaction. J. Biol. Chem. 260: 54155419.

Glöckner, G., Rosenthal, A., and Valentin, K. 2000. The structure and gene repertoire of an ancient red algal plastid genome. J. Mol. Evol. 51: 382-390.

Gopalan, V., Vioque, A., and Altman, S. 2002. RNase P: Variations and uses. J. Biol. Chem. 277: 6759-6762.

Guerrier-Takada, C., and Altman, S. 1992. Reconstitution of enzymatic activity from fragments of M1 RNA. Proc. Natl. Acad. Sci. 89: $1266-1270$.

Guerrier-Takada, C., Gardiner, K., Marsh, T., Pace, N., and Altman, S. 1983. The RNA moiety of ribonuclease P is the catalytic subunit of the enzyme. Cell 35: 849-857.

Guerrier-Takada, C., Eder, P.S., Gopalan, V., and Altman, S. 2002. Purification and characterization of Rpp25, an RNA-binding protein subunit of human ribonuclease P. RNA 8: 290-295.

Haas, E.S., Brown, J.W., Pitulle, C., and Pace, N.R. 1994. Further perspective on the catalytic core and secondary structure of ribonuclease P RNA. Proc. Natl. Acad. Sci. 91: 2527-2531.

Hall, T.A. and Brown, J.W. 2002. Archaeal RNase P has multiple protein subunits homologous to eukaryotic nuclear RNase P proteins. RNA 8: 296-306.

Hanic-Joyce, P.J. and Gray, M.W. 1990. Processing of transfer RNA precursors in a wheat mitochondrial extract. J. Biol. Chem. 265: 13782-13791.

Harris, J.K., Haas, E.S., Williams, D., Frank, D.N., and Brown, J.W. 2001. New insight into RNase P RNA structure from comparative analysis of the archaeal RNA. RNA 7: 220-232.

Hartmann, R.K., Heinrich, J., Schlegl, J., and Schuster, H. 1995. Pre- cursor of C4 antisense RNA of bacteriophages P1 and P7 is a substrate for RNase P of Escherichia coli. Proc. Natl. Acad. Sci. 92: 5822-5826.

Jayanthi, G.P. and Van Tuyle, G.C. 1992. Characterization of ribonuclease P isolated from rat liver cytosol. Arch. Biochem. Biophys. 296: $264-270$.

Kole, R. and Altman, S. 1981. Properties of purified ribonuclease P from Escherichia coli. Biochemistry 20: 1902-1906.

Laferriere, A., Gautheret, D., and Cedergren, R. 1994. An RNA pattern matching program with enhanced performance and portability. Comput. Appl. Biosci. 10: 211-212.

Lang, B.F., Burger, G., Doxiadis, I., Thomas, D.Y., Bandlow, W., and Kaudewitz, F. 1977. A simple method for the large-scale preparation of mitochondria from microorganisms. Anal. Biochem. 77: 110-121.

Lang, B.F., Ahne, F., Distler, S., Trinkl, H., Kaudewitz, F., and Wolf, K. 1983. Sequence of the mitochondrial DNA, arrangement of genes and processing of their transcripts in Schizosaccharomyces pombe. In Molecular biology of the fission yeast (eds. A. Nasim, et al.), pp. 3118-3119, Academic Press, San Diego, CA.

Lang, B.F., Burger, G., O’Kelly, C.J., Cedergren, R., Golding, G.B., Lemieux, C., Sankoff, D., Turmel, M., and Gray, M.W. 1997. An ancestral mitochondrial DNA resembling a eubacterial genome in miniature. Nature 387: 493-497.

Lang, B.F., Gray, M.W., and Burger, G. 1999. Mitochondrial genome evolution and the origin of eukaryotes. Annu. Rev. Genet. 33: 351397.

Lee, Y.C., Lee, B.J., Hwang, D.S., and Kang, H.S. 1996a. Purification and characterization of mitochondrial ribonuclease P from Aspergillus nidulans. Eur. J. Biochem. 235: 289-296.

Lee, Y.C., Lee, B.J., and Kang, H.S. 1996b. The RNA component of mitochondrial ribonuclease P from Aspergillus nidulans. Eur. J. Biochem. 235: 297-303.

Leigh, J., Seif, E., Rodriguez, N., Jacob, Y., and Lang, B.F. 2003. Fungal evolution meets fungal genomics. In Handbook of fungal biotechnology, 2nd ed. (ed. Arora D.). Marcel Dekker Inc., New York (in press).

Marchfelder, A. and Brennicke, A. 1994. Characterization and partial purification of tRNA processing activities from potato mitochondria. Plant Physiol. 105: 1247-1254.

Martin, C.A. and Lang, B.F. 1997. Mitochondrial RNase P: The RNA family grows. Nucleic Acids Symp. Ser. 36: 42-44.

Miller, D.L. and Martin, N.C. 1983. Characterization of the yeast mitochondrial locus necessary for tRNA biosynthesis: DNA sequence analysis and identification of a new transcript. Cell 3: 911917.

Morales, M.J., Dang, Y.L., Lou, Y.C., Sulo, P., and Martin, N.C. 1992. A $105 \mathrm{k}$-Da protein is required for yeast mitochondrial RNase P activity. Proc. Natl. Acad. Sci. 89: 9875-9879.

Nishida, H. and Sugiyama, J. 1993. Phylogenetic relationships among Taphrina, Saitoella, and other higher fungi. Mol. Biol. Evol. 10: 431-436.

Ojala, D., Merkel, C., Gelfand, R., and Attardi, G. 1980. The tRNA genes punctuate the reading of genetic information in human mitochondrial DNA. Cell 22: 393-403.

Pannucci, J.A., Haas, E.S., Hall, T.A., Harris, J.K., and Brown, J.W. 1999. RNase P RNAs from some archaea are catalytically active. Proc. Natl. Acad. Sci. 96: 7803-7808.

Paquin, B., Laforest, M.J., Forget, L., Roewer, I., Wang, Z., Longcore, J., and Lang, B.F. 1997. The fungal mitochondrial genome project: Evolution of fungal mitochondrial genomes and their gene expression. Curr. Genet. 31: 380-395.

Pascual, A. and Vioque, A. 1999. Functional reconstitution of RNase $\mathrm{P}$ activity from a plastid RNA subunit and a cyanobacterial protein subunit. FEBS Lett. 442: 7-10.

Peck-Miller, K.A. and Altman, S. 1991. Kinetics of the processing of the precursor to $4.5 \mathrm{~S}$ RNA, a naturally occurring substrate for RNase P from Escherichia coli. J. Mol. Biol. 221: 1-5.

Petersen, R.F., Langkjaer, R.B., Hvidtfeldt, J., Gartner, J., Palmen, W., 
Ussery, D.W., and Piskur, J. 2002. Inheritance and organisation of the mitochondrial genome differ between two Saccharomyces yeasts. J. Mol. Biol. 318: 627-636.

Puranam, R.S. and Attardi, G. 2001. The RNase P associated with HeLa cell mitochondria contains an essential RNA component identical in sequence to that of the nuclear RNase P. Mol. Cell. Biol. 21: $548-561$.

Ragnini, A., Grisanti, P., Rinaldi, T., Frontali, L., and Palleschi, C. 1991. Mitochondrial genome of Saccharomyces douglasii: Genes coding for components of the protein synthetic apparatus. Curr. Genet. 19: 169-174.

Reith, M. and Munholland, J. 1995. Complete nucleotide sequence of the Porphyra purpurea chloroplast genome. Plant Mol. Biol. Reptr. 13: 333-335.

Rossmanith, W. and Karwan, R.M. 1998. Characterization of human mitochondrial RNase P: Novel aspects in tRNA processing. Biochem. Biophys. Res. Commun. 247: 234-241.

Rossmanith, W. and Potushak, T. 2001. Difference between mitochondrial RNase P and nuclear RNase P. Mol. Cell. Biol. 21: 8236-8237.

Salavati, R., Panigrahi, A.K., and Stuart, K.D. 2001. Mitochondrial ribonuclease P activity of Trypanosoma brucei. Mol. Biochem. Parasitol. 115: 109-117.

Sbisa, E., Pesole, G., Tullo, A., and Saccone, C. 1996. The evolution of the RNase P- and RNase MRP- associated RNAs: Phylogenetic analysis and nucleotide substitution rate. J. Mol. Evol. 43: 46-57.

Schlegl, J., Hardt, W.D., Erdmann, V.A., and Hartmann, R.K. 1994. Contribution of structural elements to Thermus thermophilus ribonuclease P RNA function. EMBO J. 13: 4863-4869.

Sekito, T., Okamoto, K., Kitano, H., and Yoshida, K. 1995. The complete mitochondrial DNA sequence of Hansenula wingei reveals new characteristic of yeast mitochondria. Curr. Genet. 28: 39-53.

Shu, H.H. and Martin, N.C. 1991. RNase P RNA in Candida glabrata mitochondria is transcribed with substrate tRNAs. Nucleic Acids Res. 19: 6221-6226.

Shu, H.H., Wise, C.A., Clark-Walker, G.D., and Martin, N.C. 1991. A gene required for RNase $\mathrm{P}$ activity in Candida (Torulopsis) glabrata mitochondria codes for a 227-nucleotide RNA with homology to bacterial RNase P RNA. Mol. Cell. Biol. 11: 1662-1667.

Stark, B.C., Kole, R., Bowman, E.J., and Altman, S. 1978. Ribonuclease P: An enzyme with an essential RNA component. Proc. Natl. Acad. Sci. 75: 3717-3721.
Stribinskis, V., Gao, G.J., Sulo, P., Dang, Y.L., and Martin, N.C. 1996. Yeast mitochondrial RNase P RNA synthesis is altered in an RNase $\mathrm{P}$ protein subunit mutant insights into the biogenesis of a mitochondrial RNA-processing enzyme. Mol. Cell. Biol. 16:34293436.

Stribinskis, V., Gao, G.J., Ellis, S.R., and Martin, N.C. 2001. Rpm2, the protein subunit of mitochondrial RNase $\mathrm{P}$ in Saccharomyces cerevisiae, also has a role in the translation of mitochondrially encoded subunits of cytochrome c oxidase. Genetics 158: 573585.

Thomas, B.C., Li, X., and Gegenheimer, P. 2000. Chloroplast ribonuclease $\mathrm{P}$ does not utilize the ribozyme-type pre-tRNA cleavage mechanism. RNA 6: 545-553.

Trinkl, H., Lang, B.F., and Wolf, K. 1989. Nucleotide sequence of the gene encoding the small ribosomal RNA in the mitochondrial genome of the fission yeast Schizosaccharomyces pombe. Nucleic Acids Res. 17: 6730.

Turmel, M., Lemieux, C., Burger, G., Lang, B.F., Otis, C., Plante, I., and Gray, M.W. 1999. The complete mitochondrial DNA sequences of Nephroselmis olivacea and Pedinomonas minor. Two radically different evolutionary patterns within green algae. Plant Cell 11: 1717-1730.

Underbrink-Lyon, K., Miller, D.L., Ross, N.A., Fukuhara, H., and Martin, N.C. 1983. Characterization of a yeast mitochondrial locus necessary for tRNA biosynthesis: Deletion mapping and restriction mapping studies. Mol. Gen. Genet. 191: 512-518.

Wagner, M., Fingerhut, C., Gross, H.J., and Schon, A. 2001. The first phytoplasma RNase P RNA provides new insights into the sequence requirements of this ribozyme. Nucleic Acids Res. 29: 26612665.

Wilson, C., Ragnini, A., and Fukuhara, H. 1989. Analysis of the regions coding for transfer RNAs in Kluyveromyces lactis mitochondrial DNA. Nucleic Acids Res. 17: 4485-4491.

Wise, C.A. and Martin, N.C. 1991a. Dramatic size variation of yeast mitochondrial RNAs suggests that RNase P RNAs can be quite small. J. Biol. Chem. 266: 19154-19157.

- 1991b. Sequence analysis of Saccharomyces exiguus mitochondrial DNA reveals an RNase P RNA flanked by two tRNA genes. Nucleic Acids Res. 19: 4773.

Yokobori, S. and Pääbo, S. 1995. Transfer RNA editing in land snail mitochondria. Proc. Natl. Acad. Sci. 92: 10432-10435. 

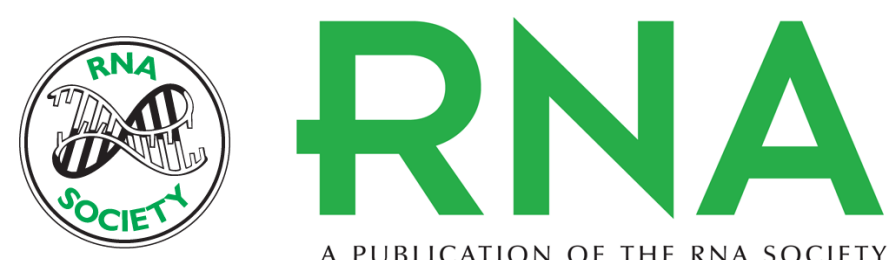

A PUBLICATION OF THE RNA SOCIETY

\section{Mitochondrial RNase P RNAs in ascomycete fungi: Lineage-specific variations in RNA secondary structure}

ELIAS R. SEIF, LISE FORGET, NANCY C. MARTIN, et al.

RNA 2003 9: 1073-1083

References This article cites 70 articles, 25 of which can be accessed free at:

http://rnajournal.cshlp.org/content/9/9/1073.full.html\#ref-list-1

\section{License}

Email Alerting Receive free email alerts when new articles cite this article - sign up in the box at the Service top right corner of the article or click here. 